REVISTA DE DERECHO UNED, núm. 2, 2007

\title{
EN TORNO A LA PRESCRIPCIÓN DEL DELITO EN DERECHO ROMANO ${ }^{29}$
}

\author{
EDOARDO VOLTERRA
}

Las fuentes del Derecho Romano, que sí conservan para nosotros numerosas leyes clásicas y bizantinas sobre la prescripción civil y nos permiten reconstruir exactamente la estructura y evolución de la institución a través de las diversas épocas, son, sin embargo, casi completamente mudas en relación con la prescripción de los delitos públicos. A excepción de algunos específicos casos en los que se ha fijado un término determinado para intentar la acusación, no se alude nunca a la existencia de una regla general que sirva en el campo del Derecho Penal. Sin embargo, por la opinión dominante se sostiene que en la época imperial se habría establecido un término de veinte años para la extinción de los delitos. Base de tal afirmación es una constitución de Diocleciano y Maximiano del 293 en materia de «crimen falsi».

L. 12 C. ad leg. Corn. de fals. 9,22 Impp. Diocletianus et Maximianus A.A. et C.C. Primo. "Querella falsi temporalibus praescriptionibus non excluditur nisi viginti annorum exceptione, sicut cetera quoque fere crimina».

Mommsen $^{30}$ considera la ley como una prueba decisiva para la existencia de una prescripción general de veinte años, pero no fija la época en que tal norma fue promulgada. Ferrini, siguiendo sus pasos, sostiene la misma tesis y concluye, «dónde y cómo se deriva esta prescripción que los emperadores afirman con carácter casi general,

29 Título original: «Intorno alla prescrizione dei reati in diritto romano», en $B u$ llettino del'Istituto di Diritto Romano Vittorio Scialoja, XXXVII, 1929, págs. 57 y ss. Traducido por Félix María Pedreira González.

${ }^{30}$ Römisches Strafrecht, pág. 489. 
lo ignoramos. Es muy fácil que se haya establecido por constituciones de príncipes después de los Antoninos ${ }^{31}$.

Esta interpretación literal de la L. 12 C. h. t. ${ }^{32}$, hoy comúnmente seguida por los autores de Derecho Penal, no es nueva en absoluto, pues se encuentra aplicada bastantes siglos antes de los escolásticos bizantinos de los Basílicos y declarada más tarde, como principio indiscutible, también por los glosadores y por los comentaristas occidentales.

Sin embargo, de un examen atento de las fuentes, me parece que tal prescripción no tenía en Derecho Romano un origen tan antiguo $\mathrm{y}$, por el contrario, debe referirse a tiempos más recientes: los textos prejustinianeos, en efecto, no sólo no vienen a apoyar la opinión dominante, sino que proporcionan una serie de indicios netamente contrarios, de los que resultaría la existencia de un sistema completamente diferente en el Derecho clásico.

La constitución de Diocleciano y Maximiano no tendría el valor que se le quiere atribuir, sino que la declaración contenida en ella se debería a la inserción, por parte de los compiladores de Justiniano, de una frase que, cambiando profundamente el texto y el significado originario de la ley, habría afirmado un principio inexistente en el siglo III.

Me ciño en esta breve nota a exponer los elementos sobre los que se basa esta tesis y, al mismo tiempo, a investigar el sistema de la prescripción de los delitos en el Derecho Penal Romano.

$$
* * *
$$

En primer lugar, respecto a nuestra L. 12 C. h. t., se puede observar que la prescriptibilidad de veinte años del delito de "falsum» no existía en el Derecho clásico. Los numerosos fragmentos en materia de falsedad, contenidos en las colecciones prejustinianeas y en la compilación, no aluden nunca a la existencia de este término para la proposición de la acusación, silencio que contrasta, de forma extraña, con las numerosas declaraciones que los jurisconsultos efectúan, en

31 FERRINI, Diritto penale romano. Teorie generali. Milano 1899 pág. 342.

32 V. también ESMEIN, Le délit d'adultère à Rome ecc. (Mélanges d'histoire du droit. Paris 1886. pág. 129 n.1), el cual cita en apoyo de la L.27 C. h. t., un pasaje de SuETONIUS, Tib. cap. 49. En cambio, me parece que el pasaje constituye más bien un argumento en contra, y prueba que también después de veinte años podía haber lugar a la acusación criminal «... condemnatam et generosissiman feminam Lepidam in gratia Quirini consularis praedivitis et orbi, qui dimissam eam e matrimonio post vicensimum annum veneni olim in se comparati arguebat». 
cambio, respecto de las acciones fiscales, en las que, sin embargo, la prescripción de veinte años es realmente admitida. La posterior falta de cualquier alusión a una prescripción parece tanto más grave cuando se piensa que la mayor parte de los fragmentos examinados tratan del "falsum» en materia sucesoria y, precisamente, en relación con la invalidez del testamento. Ahora bien, si en verdad este término hubiese existido, sería auténticamente extraño que los juristas, resolviendo cuestiones prácticas de esta especie, no se remitiesen nunca a un elemento de tanta importancia como el tiempo dentro del cual se puede intentar la acusación, y, sin embargo, hablasen de un delito de "falsum" como si el mismo no estuviese sujeto a ninguna limitación de tiempo.

Por otra parte, además de estas consideraciones de carácter general, algunas leyes, aún no relacionadas con la cuestión, vienen netamente a desmentir la L. 12 C. h. t.

En una constitución de Constantino, que, estableciendo algunas normas de procedimiento para el juicio de falsedad, nos expone el sistema precedente, se contiene, en efecto, la declaración explícita de que la acusación para el supuesto de falsedad de instrumentos procesales no estaba sujeta a ningún término, sino que podía proponerse en cualquier momento.

L. 2 pr. C. Th. ad leg. Corn. de fals. 9,19 Imp. Costantinus A. ad Maximum p. u. "Cum in praeterito is mos in iudicis servaretur, ut prolatis instrumentis, si ea falsa quis diceret, a sententia iudex civilis controversiae temperaret eoque contingeret, ut imminens accusatio nullis clausa temporibus petitorem possessoremve deluderet, commodum duximus, ut, etsi, alteruter litigantium falsi strepitum intulisset, petitori tamen possessorive momentum prolatorum instrumentorum conferret auctoritas, ut tunc civili iurgio terminato secunda falsi actio subderetur».

La afirmación del emperador "accusatio nullis clausa temporibus», me parece demasiado clara para que queden dudas sobre la cuestión.

Significativa es también una ley de Paolo, contenida en el Digesto bajo el título "de lege Cornelia de falsis», que afirma que la acusación por el delito de suposición de parto, absorbido en la legislación imperial bajo la figura del «falsum» ${ }^{33}$, no estaba limitada por ninguna

33 L. 30 § 1 D, ad Leg. Corn. de fals. 48,10; L. 10 C. h. t. Cfr. CostA, Crimini e pene da Romolo a Giustiniano, Bologna 1921 pág. 147. 
prescripción y podía tener lugar, incluso, en caso de muerte de aquéllos que habían simulado el parto.

L. 19 \& I D. l. Com. de fals. 48,10. (Paulus libro quinto sententiarum) «Accusatio suppositi partus nulla temporis praescriptione depellitur, nec interest, decesserit nec ne ea, quae partum subdidisse contenditur».

Además de la declaración de este fragmento (que, sin embargo, el jurisconsulto bizantino Teodoro, siempre sobre la base de la L. 12 C. h. t., interpreta como referido al único caso allí comprendido) ${ }^{34}$, un indicio indirecto de la imprescriptibilidad de la acusación de falsedad en el Derecho clásico se encuentra en una constitución de Diocleciano y Maximiano, los mismos emperadores a los que se atribuye la $\mathrm{L}$. 12 C. h. t.

L. 17 C. h. t. Impp. Diocletianus et Maximianus A. A. et C. C. Menelao «Sicut falsi testamenti vel codicillorum scriptura temporis intervallo firmari non potest, ita vera quae iure subsistit non evanescit. I) $\mathrm{Si}$ itaque de fide delicti vel per accusationem vel per privatum iudicium quereris, rector provinciae tunc demum exhiberi de quibus interrogatio fieri potest iubebit, si prius ceteris indiciis fuerit commotus".

Después de haber declarado que el tiempo no puede subsanar la falsedad del testamento o del codicilo, se dispone que el gobernador de la provincia, ante el cual sea intentada la acusación criminal o planteada la acción civil, debe hacer llamar a aquéllos «de quibus interrogatio fieri potest», cuando existan los indicios suficientes. Está claro, por tanto, que Diocleciano, hablando de la "accusatio falsi", tras el principio de la imprescriptibilidad afirmado en la introducción, parece considerar también esta acusación sometida al mismo principio iy no suponer en absoluto la existencia de un término de veinte años!

Pasando ahora a la segunda afirmación de la L. 12 C. h. t., es decir, que la prescripción de veinte años, además de al «falsum», se aplicaría a casi todos los demás «crimina» («sicut cetera quoque fere criminan), debemos observar como tampoco esta norma responde para nada a lo que parece ser la realidad de las cosas en la época de Diocleciano.

${ }^{34}$ Cfr. en efecto la glosa Bas. LX, 41, 19, 4, 2 (Heimb. V, 786) referido en pág. 50 n. 1 . 
$\mathrm{Al}$ margen de la así denominada «longi temporis praescriptio», que es una institución de Derecho privado y que no rige para los delitos, no encontramos de hecho una sola clase de juicios para los que tuviese valor esta norma; únicamente las causas con el Fisco, que prescribían por el transcurso de veinte años. Es, por el contrario, una disposición que los jurisconsultos clásicos repiten varias veces en sus fragmentos y se nos presenta como un caso único introducido por el emperador Antonino Pío y por sus sucesores, Marco Aurelio y Lucio Vero.

L. I. §§ 3-4 D. de i. f. 49, 14. Callistratus libro primo de iure fisci "Praescriptio autem viginti annorum, quae etiam circa requirendorum adnotatorum bona observatur, ex constitutione divi Titi solet ex eo numerari, ex quo quid ad fiscum pertinere potuit. Causae autem, quae statim motae sunt et tracta e ultra vicensimum annum, differri possunt etiam post vicensimum annum".

L. 2 D. de r. v. a.d. 48, 17 Macer libro secundo publicorum "Anni spatium ad occupanda bona eius, qui requirendus adnotatus est, pertinet. Sed si per viginti annos fiscus bona non occupaverit, postea praescriptione vel ab ipso reo vel ab heredibus eius submovebitur».

L. 3 eod. Marcianus libro secundo se publicis iudiciis «quamcumque enim quaestionem apud fiscum, si non alia sit propria praescriptio, viginti annorum silentio praescribi divi principes voluerunt".

\section{4. eod.}

Los títulos del Código VII, 33, («de praescriptione longi temporis decem vel viginti annorum»); 34 («in quibus causis cessat longi temporis praescriptio»); 35 («quibus non obiciatur longi temporis praescriptio») no contienen una sola mención a delitos que resulten totalmente excluidos de la prescripción de veinte años.

Sin embargo, por lo que se refiere a las acusaciones criminales en el Derecho clásico, los casos de prescripción son poquísimos, todos claramente indicados en las fuentes y para ninguno de los cuales, subráyese, está vigente el término de veinte años.

Estos son: 1) adulterio. a) En la acusación contra la mujer, cuando se trata de la "accusatio" especial «iure mariti vel patris», la prescripción es de 60 días. Para la «accusatio iure extranei», 6 meses. En ambos casos, si la acusada está casada, el término es hábil y comienza a transcurrir desde el momento del divorcio; si es viuda, desde el momento del delito. Después de cinco años sin interrupción, aunque los 60 días hábiles no hayan transcurrido, la acusación está 
definitivamente prescrita. b) En la acusación contra el hombre, el término es de cinco años, sin interrupción, desde el momento del delito $^{35}$. L. 15 § 2 D. ad leg. Iul. de ad. 48, 5; L. 4 § I D. eod. ${ }^{36}$; L. I § 10 D. ad s. c. Turpill. $48,16^{37}$.

2) Peculado: también esta prescripción es de cinco años y aparece como excepcional frente a otros delitos.

L. 9 D. ad leg. Iul. Pec. 48, 13 Venuleius Saturninus libro secundo iudiciorum publicorum «Peculatus crimen ante quinquennium admissum obici non oportet».

3) Otra prescripción de cinco años, que Venuleio Saturnino afirma que ha sido establecida por un senadoconsulto del II d.C., rige en la acusación contra el "extraneus» que tenga abierto el testamento de un muerto antes de la "quaestio" ordenada por el senadoconsulto Silaniano. Como declara sin embargo el mismo jurisconsulto, se trata de un término excepcional aplicado sólo a favor del «extraneus», ya que la acusación está siempre abierta contra los familiares ${ }^{38}$ del muerto.

L. 13 D. de S. c. Sil. 29, 5. Venuleius Saturninus libro secundo de publicis iudiciis. "In cognitione aperti adversus senatus consultum testamenti eius, qui a familia sua occisus dicatur, quinquennii tempus constitutum est senatus consulto Tauro et Lepido consulibus: quod tamen ad extraneos pertinet, namque eos, qui parricidii poena teneri possunt, semper accusare permittitur eodem senatus consulto".

4) Algunos delitos privados introducidos por el Pretor: a) acción de injurias prescriptible en un año L. $17 \S 6$ D. de in. 47,10 . b) acción por corrupción procesal, limitada a un año por la pena del cuádruplo, imprescriptible por la pena del «simplum».-L. I pr. D. de col. 3, 6.

Esta última categoría nos interesa muy poco en relación con la declaración de Diocleciano, puesto que el emperador, con la frase «sicut cetera quoque crimina», parece referirse, según la terminología de la época, sólo a los "crimina publica», no a los delitos privados.

35 Cfr. sobre el argumento Esmein, op. cit. Pág 128 sgg.; Volterra, Per la storia dell'accusatio adulterii iure mariti vel patris (Studi economico-giuridici della R. Università di Cagliari 1928) pág. 9 sgg.

36 Sobre la probable interpolación del texto cfr. el estudio citado pág. $54-55$ n. 2.

37 V. también L. 12 § 6 D. ad leg. Iul. de ad. 48, 16; L. 16; L. 30 \& eod.; L. 37 \& 1 D. de minor. 4, 4; L. 14 pr. D. qui et quib. man. 40, 9; Coll IV, 4, 2; L. 5 pr. C. ad. leg Iul. de ad. 9, 9; L. 6; L. 21 eod.; Tac. Annal. 11, 85.

38 El pasaje nos habla de aquellos que «parricidio poena teneri possunt». Está claro por lo tanto que se trata de los descendientes, como justamente interpretan también los «Basilici» XXXV, 16, 12 (Heimb. III 627). 
Fuera de los casos que hemos enumerado, la acusación criminal no está sometida en el Derecho clásico a ninguna limitación de tiempo. Las fuentes y el mismo sistema del Derecho Romano nos proporcionan una serie de indicios que, en verdad, no dejan lugar a duda sobre ello.

Que de hecho en sus orígenes la prescripción de los delitos era una institución completamente desconocida para los romanos, es un hecho conocidísimo y admitido de forma unánime por todos los autores, que, con la doctrina dominante, afirman para la época de Diocleciano el término general de veinte $\operatorname{años}^{39}$. En los numerosos procesos que se desarrollan bajo la República, no encontramos una sola vez apuntada la posibilidad de invocar una prescripción temporal para excluir la acusación, e incluso una serie de ejemplos, como el de Cayo Rabirio, llevado a juicio después de 37 años de cometido el delito $^{40}$, son significativos en este sentido.

Un argumento posterior de gran valor es, según mi opinión, el paralelo que podemos extraer del sistema de las obligaciones en Derecho privado. La obligación romana y las antiguas obligaciones civiles son imprescriptibles y mantienen esta característica, puramente «quiritaria», por un periodo largo en el desarrollo del Derecho, reaccionando contra las instituciones extrañas que intentaban sofocar cada vez más el principio. Ahora bien, la obligación tiene sus orígenes en el Derecho Penal; como es sabido, sus fuentes primitivas son los delitos y es sólo en una etapa histórica posterior cuando se separa de ellos definitivamente, asumiendo un carácter propio, pero conservando para siempre las huellas de su antigua función. No hay quien deje de ver en este principio de la imprescriptibilidad de las obligaciones, mantenido rigurosamente en la época clásica, un indicio significativo del que debió ser el concepto originario romano en materia de delitos, es decir, que el transcurso del tiempo no influye en la punibilidad del acto delictivo.

Otra prueba que se puede citar en este sentido es la normal transmisibilidad activa de las "actiones poenales», mantenida para algunas de ellas a través del Derecho clásico e, incluso, en el Derecho justinianeo. El hecho de que en los herederos del sujeto pasivo del delito perdure siempre la acción contra el culpable, confirma también que el elemento del tiempo no tenía originariamente importancia para cancelar el delito, ni el principio podía ser distinto para los «crimina publica».

39 Mommsen, o.c.; FerRini, o.c. pág. 341.

40 CIc., Pro Rabirio, cap. 9. FERRINI, op. cit., pág. 341 n. 4. 
Este sistema originario, que encontramos en vigor durante todo el periodo republicano, no parece que fuera suprimido en el Derecho imperial de la época clásica. Al menos, no sólo ninguna fuente apunta a un cambio operado en este terreno del Derecho penal, sino que, por el contrario, tenemos una serie de pruebas en sentido netamente opuesto. Las cartas de Plinio a Trajano, citadas ya por los tratadis$\operatorname{tas}^{41}$, constituyen un documento de gran importancia para demostrar cómo en el Derecho imperial, también en los casos en que se sentía la necesidad de anular o, por lo menos, de disminuir la condena después de que hubiese transcurrido un cierto tiempo desde el hecho, faltasen totalmente medios jurídicos ordinarios para llevar a la práctica aquello y se estuviese constreñido a recurrir a medidas excepcionales. En los títulos «de accusationibus et inscriptionibus» del Código Teodosiano, del Digesto y del Código Justinianeo, donde se enumeran las diversas causas que podían conducir a inadmitir la «accusatio», no aparece ni una sola vez la extinción por el transcurso de un determinado periodo de tiempo. Declaraciones explícitas, que revelan el régimen clásico, las tenemos en algunos textos del Digesto a propósito del delito privado del hurto y del parricidio.

Así, Ulpiano, en la L. 41 \& 2 D. de furt. 47, 2 afirma que la «actio furti» permanece en pie durante toda la vida del reo, independientemente, por lo tanto, del transcurso de un determinado periodo de tiempo ("quamdiu vivit is qui furtum fecit, non perit furti actio").

En el pasaje de Venuleio Saturnino, que hemos examinado ya, tras la norma que admite la prescripción para el delito de apertura del testamento en el caso del extraño, se añade: "quod tamen ad extraneos pertinet. namque eorum qui parricidii poena teneri possunt, semper accusatio permittitur». Es claro que esta declaración se ha llevado a cabo, no ya con el fin de afirmar una norma especial, sino en contraposición a cuanto precede, justamente para mostrar cómo la prescripción a favor del extraño es una medida excepcional frente al que es el sistema normal. Tampoco me parece que constituye un argumento contrario la observación de Matthaeus, tomada también por Ferrini, a propósito de este texto, es decir que el «semper» deba referirse a la prescripción de veinte años frente a la prescripción de quince años más breve. Es necesaria una aclaración en este punto: que en el Derecho justinianeo, donde, como veremos, parece auténticamente admitida por una ley una prescripción general de veinte años, el

41 Epist. 31 y 32. Sin embargo ese nos muestra más que otro la carencia en el Derecho Romano de otro instituto conexo a aquel que estamos examinando, a saber la prescripción de la condena penal. Cfr. FERRINI o. c. pág. 345 sg. 
"semper» tenga este significado, es cierto; pero que lo tenga también en el Derecho clásico, en el que ninguna ley nos declara la existencia de un término general, es una afirmación arbitraria, que presupone ya demostrada, sin más, la existencia en aquella época de la prescripción de veinte años. El adverbio usado aquí a continuación por el jurisconsulto es ciertamente demasiado explícito para dejar alguna duda sobre el valor originario del pasaje.

En cuanto a la L. 10 D. l. Pomp. de parr. 48, 9 de Paolo, que recoge con las mismas palabras la última frase de la L. 12 D. de S. c. Sil. 29, $5^{42}$, se observa que esta declaración, realizada por los compiladores como norma propia, debía, originariamente, formar parte de un texto más largo, en el que, como en el pasaje de Saturnino, se quería destacar el régimen normal frente a la prescripción especial. No debe descartarse que también aquí el jurisconsulto se ocupase del término establecido para la apertura del testamento contra el senadoconsulto.

Otro fragmento, que, también por contraposición a la prescripción excepcional establecida para el adulterio y el estupro, nos muestra el régimen normal vigente para el resto de delitos, es la L. $30 \S 9$ D. ad. Iul. de ad. 48, 5 de Ulpiano. Después de haber hablado del término de seis meses y de los 5 años, establecido por la «Lex Iulia», distingue del estupro el caso del «crimen vis», añadiendo:

(Ulpianus libro quarto de adulteriis). «Eum autem, qui per vim stuprum intulit, vel mari vel feminae, sine praefinitione huius temporis accusari posse dubium non est, cum eum publicam vim committere nulla dubitatio est ${ }^{43}$.

Finalmente, el recuerdo del antiguo carácter de imprescriptibilidad de los delitos reaparece todavía vivo en los escolios de los jurisconsultos bizantinos, los cuales, después de que el principio hubiese cambiado completamente, sienten la necesidad de declararlo todavía referido a ciertos delitos ${ }^{44}$.

${ }^{42}$ Paulus libro singulari de poenis omnium legum «Eorum qui parricidii poena teneri possunt, semper accusatio permittiturn.

${ }^{43}$ En cuanto a la L. 2 C. de v. et c. 4, 61, aludida por Ferrini (o. c. pág. 342) como otro ejemplo de prescripción de los delitos, la misma no me parece tener ninguna importancia para nuestra cuestión ya que establece simplemente el término de cinco años para la reclamación por parte del Fisco del «commissum». Se trata, como se ve claramente de una norma que tiene importancia solo para el proceso privado, no ya para el penal. Impp Severus et Antoninus AA. Iunio. «Neque commissum, quod ante quinquennium factum dicitur, si lis anticipata non est, vindicari potest, neque pro re, quae in commissi causam cecidit, si ipsa non extat nec dolo supprimatur, pretium peti potest». Cfr. también L. 1 C. Th. de quinq. praescr. 4, 15.

${ }_{44}$ Cfr. ad es. Bas. LX, 41, 47, 3 (Heimb. V, 795). 


\section{$* * *$}

Tratado así rápidamente el sistema clásico, pasamos a observar más detenidamente nuestra L. 12 C. h. t. Hemos visto, a partir del breve examen que hemos realizado de las fuentes, como nada autoriza a considerar cambiado en el Derecho imperial el principio vigente en la época de la República respecto a la "praescriptio criminum». El sistema que resulta en el Derecho Penal inmediatamente anterior a Diocleciano es, en efecto, el siguiente: excepto algunos casos taxativamente fijados por la ley, los delitos son imprescriptibles.

En el mismo tiempo de las leyes de Diocleciano y de sus sucesores, parece claro que, contrariamente a cuanto se afirma en el texto examinado, la querella falsi, en el tercer y cuarto siglo, no estaba sujeta a plazo alguno.

Y entonces, ¿cuál es el valor que debe atribuirse a la constitución de Diocleciano y Maximiano? La frase «sicut cetera quoque fere crimina», referida a la precedente "nisi viginti annorum exceptione", entra, en efecto, netamente en contraste con el sistema expuesto y con las afirmaciones que encontramos en leyes posteriores. Pero la misma frase aparece perfectamente coherente, si la enlazamos, no ya con el inciso "nisi-exceptione», sino a la declaración "querella falsi temporalibus praescriptionibus non excluditur», de modo que se da a la ley el significado verdaderamente conforme al Derecho de la época: que, a excepción de los casos determinados de prescriptibilidad ("fere»), todas las acusaciones son perpetuas.

Por otra parte, la frase "nisi-exceptione» me parece gravemente sospechosa de ser espuria. La misma tiene, en efecto, como denotaría el característico "nisi», con el que se inicia, toda la apariencia de uno de aquellos incisos que se introducen frecuentemente en los textos originales romanos, cambiándole profundamente el significado.

Y también dudosa me parece la palabra «exceptio», utilizada aquí para señalar la "praescriptio». En la época de Diocleciano, "exceptio» tiene un significado y un carácter técnico determinado, e indica una institución propia del proceso formulario. Ahora bien, es difícil que, dado el sistema del juicio criminal y la posición que en él asume el acusador frente al reo, tan distinta de la existente entre el actor y el demandado en el proceso privado, se pudiese aplicar este término de "exceptio» a la "praescriptio criminum». En el proceso criminal, los elementos a deducir en juicio no son abandonados a la voluntad de las partes, sino que el magistrado tiene una función ab- 
solutamente preminente: una vez propuesta la acusación, es a él a quien corresponde examinar la causa para decidir si debe haber lugar a la inscripción del reo en las listas de los acusados. La acusación, después de la Ley Julia, debe ser redactada en un especial libelo, en donde, como nos declara Paolo en la L. 3 D. de acc. et inscr. 48, 2, viene, entre otras cosas, indicado el día en el que se ha cometido el acto incriminado. Todo indica, por lo tanto, que la "praescriptio criminum» era la mayor parte de las veces aplicada por el magistrado mismo, sin necesidad de que viniese opuesta por el imputado; por lo demás, también en este último caso aparecía siempre como un acto del magistrado, que declaraba inadmisible la "accusatio", y no ya como una pretensión contraria al demandado, dirigida a eludir la condena.

Este sistema nos muestra como los romanos no pudieron atribuir a la institución de la prescripción temporal el carácter y el funcionamiento de la "exceptio». Por otra parte en ningún texto clásico o dioclecianeo, excepto la L. 28 C. ad leg. Iul. de ad. 9, 9, manifiestamente interpolada ${ }^{45}$, se emplea el término "exceptio" para aludir a la "praescriptio» temporal. Sólo en la última época, cuando ya, con la imposición del procedimiento «extra ordinem» respecto del procedimiento formulario, se pierde el concepto originario de "exceptio», se produce este intercambio entre las dos palabras.

La constitución de Diocleciano y Maximiano nos parece, por tanto, acorde con el Derecho vigente en aquel tiempo, que habría sido del siguiente tenor originariamente:

«Querella falsi temporalibus praescriptionibus non excluditur sicut cetera quoque fere crimina".

$$
* * *
$$

Si el Derecho clásico y dioclecianeo seguía el principio de la imprescriptibilidad de los delitos, es cierto que en el Derecho del Bajo Imperio este sistema parece cambiar completamente, ya que encontramos establecido por primera vez un término general, transcurrido el cual, el delito no puede ser perseguido más. Un cambio en este sentido es admitido por la doctrina dominante que, de acuerdo, como es natural, con su tesis, se limita sólo a afirmar que el término de veinte años para la misma, vigente ya desde la época dioclecianea, habría sido alargado a una cifra superior, a la "praescriptio triginta annorum», según algunos, y a la "praescriptio quadraginta annorum», se-

45 V. Volterra, Nota critica alla L. 28 (29) C. ad leg. Iul. de ad. 9,9 Spoleto 1929. 
gún otros. A esta última opinión, sostenida por Wächter, se adhiere FERRINI $^{46}$, el cual, rechazando la posibilidad de una prescripción de treinta años, se basa para sostener su tesis en la L. 4 C. de praescr. 7, 39 , donde «se dice explícitamente que cualquier derecho público y privado se extingue con el perpetuo silencio de cuarenta años».

La tesis, por mucho que sea sostenida por la generalidad de los autores, no encuentra sin embargo ninguna confirmación en los textos romanos y bizantinos y, por lo tanto, es totalmente arbitraria y carente de una base segura.

Retomado el estudio "ex novo» de las fuentes, debemos, sobre todo, subrayar cómo estas son muy inciertas e imprecisas: respecto a esta cuestión, ninguna de las constituciones, promulgadas por los emperadores en el Bajo Imperio para sancionar y regular la institución de la "praescriptio", muestra que esta institución se pueda aplicar a los juicios penales en general. Si, en efecto, la L. 4 C. de praescr. 7, 39 de Anastasio no menciona expresamente los delitos, el mismo silencio parece encontrarse en la precedente L. 3 eod. de Onorio y Teodosio, que introduce en el Derecho Romano la prescripción de treinta años. Ni en la declaración de esta última, aún aparentemente general y comprensiva, "si qua res vel ius ali quod postuletur vel persona qualicumque actione vel persecutione pulsetur, nihilo minus erit agenti triginta annorum praescriptio metuenda», es posible ver una explícita referencia a los juicios penales, ya que la constitución entera parece referirse sólo a juicios privados y, por otra parte, la expresión "persona.. persecutione pulsetur», sobre la que se quería especialmente llamar la atención, no tiene en este sentido ningún valor específico, dado que el término "persecutio» es usado en los textos romanos para indicar cualquier clase de juicios $\mathrm{y}$, preferentemente, aquellos privados.

También otros textos, citados para demostrar cómo en el Bajo Imperio se aplicaba a los delitos el término de treinta años, quedan bastante lejos de ofrecer una prueba segura. Así, la Novela de Valentiniano de episcopali iudicio, que se ocupa de las causas civiles y criminales de los clérigos, declarando que cualquier acción debe considerarse extinguida con la "praescriptio $X X X$ annorum», se refiere evidentemente, como parece derivarse del contexto, sólo a las acciones privadas ${ }^{47}$. La L. I § I d. C. de ann. ex. 7, 40 de Justiniano, donde

46 op. cit. pág. 344.

$47 \mathrm{Ni}$ el hecho de que la antigua interpretación a esta ley, catalogando algunas acciones antiguamente perpetuas y ahora prescriptibles, ponga entre estas a la $a$. ho- 
se ordena que dentro del plazo de treinta años se vuelvan a incluir también la «a. furti» y la «a. vi bonorum raptorum», demuestra sólo, tras la confrontación con la L. $41 \S 2 \mathrm{D}$. de furt,. 472 de Ulpiano, que para la "a. furti» se aplica un criterio distinto del que está vigente bajo los Severos, pero no tiene importancia para nuestra cuestión, ya que se refiere a dos acciones privadas, extinguibles por tanto después de 30 años. Finalmente un escolio de los Basílicos, que, comentando la L. 19 D. de fals. 48, 10 de l. Corn., observa que las palabras «nulla temporis praescriptione continetur» deben interpretarse en el sentido de que no exista un plazo inferior a los 30 años y al mismo tiempo considera a la L. 12 C. h. t. como una norma especial aplicable sólo al "crimen falsi» ${ }^{48}$, es demasiado incierto y vago para poderse asumir como referencia precisa al sistema vigente en la época justinianea, y no considerarlo más bien como fruto de una errada interpretación por parte del jurisconsulto bizantino. Como tal, de hecho, negándole cualquier valor, parece considerarlo también Ferrini.

$\mathrm{Si}$, por tanto, falta en la compilación cualquier referencia a una prescripción distinta de los delitos, la principal fuente para la construcción dogmática del Derecho Penal justinianeo debe ser necesariamente nuestra L. 12 C. h. t., la cual, precisamente por su interpolación, nos muestra el sistema vigente en el siglo VI frente al principio clásico de la imprescriptibilidad. La declaración de que la "querella falsi» se extingue en veinte años, "sicut quoque cetera fere crimina», es, en verdad, demasiado explícita para no admitir sobre su base la regla general de la prescripción de veinte años de los delitos. Los jurisconsultos bizantinos parecen proporcionarnos una confirmación de la existencia de la regla en el Derecho post-justinianeo y de su carácter general. Teodoro, en efecto, comentando la constitución en la tra-

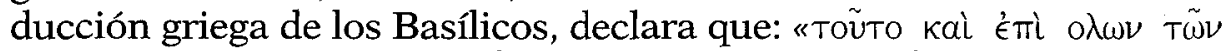

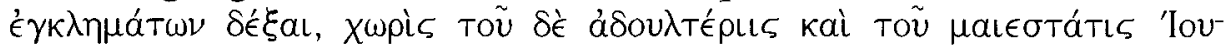
$\lambda i_{\text {ou }{ }^{49}}$, y repite también en otros escolios la misma norma ${ }^{50}$. También

micidii demuestra que tal prescripción debía ser necesariamente de treinta años. Cuiacio (De diversis temporum praescripti onibus et terminis cap. XXX Opera Omnia ed. Venecia I 485) añade extrañamente basándose en la L. 12. C. eod. civilis scilicet (nam crimen vicennio extinguitur).

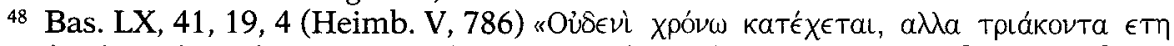

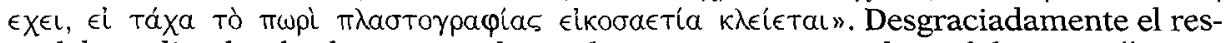
to del escolio, donde el jurisconsulto se disponía a comentar las palabras "nullo tempore», nos ha llegado mutilado en el manuscrito.

49 Bas. LX, 41, 47, 1 (Heimb., V, 795).

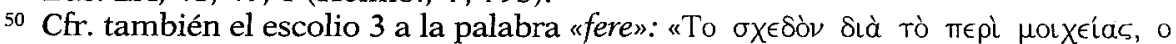

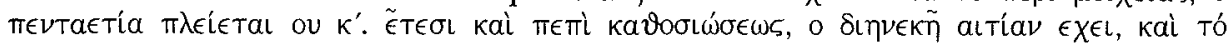

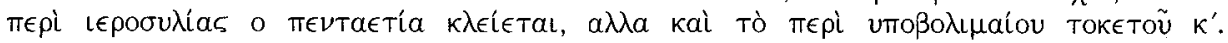




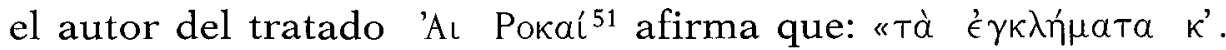

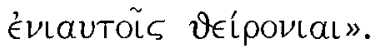

Naturalmente, acogiendo este principio en el derecho de la compilación, los fragmentos clásicos del Digesto y del Código adquieren un nuevo significado: vienen de hecho a tener un valor distinto según que se consideren como fuentes del Derecho clásico o como parte integrante de la legislación justinianea. En este segundo caso no deben interpretarse en su rígido sentido literal, sino considerados siempre como sometidos a la cláusula general de la "praescriptio $X X$ annorum».

Sin embargo, en el nuevo régimen no faltan excepciones. Se conservan las prescripciones quinquenales, ya precedentemente enumeradas, que existían en el Derecho clásico en los casos taxativamente determinados. Disposiciones especiales rigen, por lo tanto, para el crimen de apostasía, surgido sólo en el Derecho cristiano. Éste, a diferencia de los otros, puede ser perseguido sin ninguna limitación de tiempo durante toda la vida del culpable y, para los efectos civiles, también contra el difunto con el fin de invalidar su testamento: en este último caso se conceden, como pasa en el resto de las acciones de «inofficioso testamento», 5 años, a partir del momento de la muerte ${ }^{52}$.

L. 4 pr. C. de apost. 1, 7 (= L. 7 C. Th. de apost. 16, 7) Impp. Theodosius et Valentinianus A. A. Basso pp. "Apostatarum sacrilegum nomen singulorum vox continuae accusationis incesset et nullis finita temporibus huiuscemodi criminis arceatur indago. 2) In tantum autem contra huiuscemodi sacrilegia perpetuari volumus actionem, ut universis ab intestato venientibus etiam post mortem peccantis absolutam vocem insimulationis congruae non negemus: nec illud patiemur obstare, si nihil in constestatione profano dicatur vivente perductum» (a. 426).

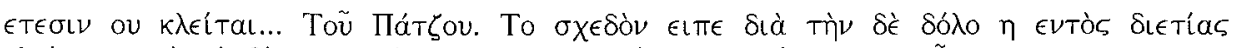

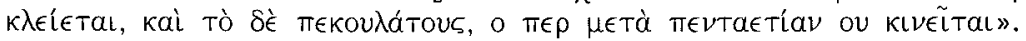

También estos dos escolios muestran claramente que tanto Teodoro, como el otro jurisconsulto se basan exclusivamente en la L. $12 \mathrm{C}$. h. t., que la interpretan en su sentido literal. También es importante el comentario a la L. 19 § 1 D. de l. C. de fals. 48, 10, in Bas. LX, 41, 19, 4, 2 (Heimb. V, 786) arriba referido. $9,22$.

No hay duda que tal afirmación es deducida también de la L. 12 C. ad. Corn. de fal.

51 cap. XXXVII, 7.

52 L. 2 C. de apost. 1, 7 (= L. 4 C. Th. h. t. 16, 7). Para otros casos, en que ya en el Derecho clásico se concede la acusación también después de la muerte del culpable, a fin de conservar los efectos civiles. V. FERRINI, Diritto penale romano. Esposizione storica e doctrina. Milano, 1902 pág. 164-165. 
También el "crimen maiestatis» parece no estar sujeto a prescripciones temporales. Al menos, en el Código justinianeo, se declara que se puede intentar también después de la muerte del culpable ${ }^{53}$, e imprescriptible lo consideran además los escolásticos bizantinos, que parecen referirse al sistema vigente en la época de Justiniano.

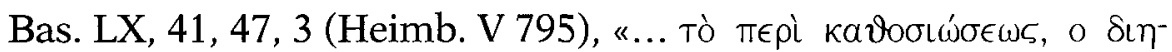
$\nu \in \kappa \tilde{n}$ aipíav $\in \chi \in \mathrm{L} \ldots »$

En conclusión, por medio de esta investigación resulta claramente de las fuentes el principio vigente en el Derecho clásico de la imprescriptibilidad de los delitos, mientras que, respecto al sistema del Derecho justinianeo, encontramos, a través de la interpolación de la constitución dioclecianea, la existencia de un nuevo y distinto principio que parece conservarse también en el posterior Derecho bizantino.

${ }^{53}$ L. $6 \S 2$ C. ad leg. Iul. maiest. 9, 8. 